\title{
Transmission of Alternaria brassicicola to Cabbage by Flea Beetles (Phyllotreta cruciferae)
}

\author{
H. R. Dillard, A. C. Cobb, and J. S. Lamboy, Department of Plant Pathology, Cornell University, New York State \\ Agricultural Experiment Station, Geneva 14456
}

\begin{abstract}
Dillard, H. R., Cobb, A. C., and Lamboy, J. S. 1998. Transmission of Alternaria brassicicola to cabbage by flea beetles (Phyllotreta cruciferae). Plant Dis. 82:153-157.

In 1995 and 1996, flea beetles (Phyllotreta cruciferae) were observed in the field feeding on cabbage plants that were infected with Alternaria brassicicola. Flea beetles were captured in glass vials, etherized, and placed on agar media for isolation of A. brassicicola. In 1995, A. brassicicola was isolated from 13 out of $69(18.8 \%)$ flea beetles in the first test and 38 out of $132(28.8 \%)$ in the second test. In 1996, flea beetles were collected nine times during the growing season, and the isolation frequency increased from 0 to $77 \%$ as the crop approached maturity. In another study, flea beetles were collected from a field of $A$. brassicicola-infected cabbage, enclosed in plastic bags containing potted healthy cabbage plants, and then placed on a shaded greenhouse bench for 6 days. Alternaria leaf spot developed on plants that were infested with the contaminated flea beetles. Feces obtained from flea beetles that fed on cabbage infected with A. brassicicola contained intact and broken conidia of A. brassicicola and undigested pieces of cabbage leaf. The conidia were viable after passing through the flea beetles, as evidenced by their germination on the glass slides used for collecting the feces. Conidia of $A$. brassicicola were observed by scanning electron microscopy on all parts of flea beetle bodies, including wings, mouthparts, antennae, and legs.
\end{abstract}

Cabbage (Brassica oleracea L. var. capitata L.) is an economically important vegetable crop grown in New York, with an annual value of $\$ 45$ million. New York is the number one producer of cabbage for the fresh market in the United States, with approximately 5,700 ha planted for the fresh market and 1,200 ha planted for processing into sauerkraut annually. There are several insects $(5,18,21)$ and diseases $(4,5,7,11,15,18)$ that can significantly reduce yield and quality of cabbage, and Alternaria leaf spot is among them.

Alternaria leaf spot of cabbage is caused by Alternaria brassicae (Berk.) Sacc. or Alternaria brassicicola (Schwein.) Wiltshire $(11,15,17)$. Both species have worldwide distribution on cruciferous hosts, but A. brassicicola is the predominant species on cabbage grown in New York (11). The fungus may be seedborne as a surface contaminant (20), as conidia lodged in cavities and depressions of the hilum (12), or as mycelium in infected testa and embryos $(12,15)$. Other sources of inoculum include infested debris in soil, infected weeds, and nearby infected cruciferous crops $(11,17,20)$. Symptoms, such as small

Corresponding author: H. R. Dillard

E-mail: hrd1@ cornell.edu

Accepted for publication 15 October 1997.

Publication no. D-1997-1125-03R

(C) 1998 The American Phytopathological Society dark spots on the seedling stem and eventual damping-off or wirestem, may occur immediately after germination of the seed (2). Leaf spots vary in size from pinpoints to $4 \mathrm{~cm}$ in diameter. The lesions enlarge in concentric rings and are black in color. Defoliation of the outer leaves may occur on severely infected plants, and extensive trimming may be required to remove infected leaves from the cabbage head at harvest. In susceptible cultivars, significant yield loss and quality reduction may occur.

The conidia of A. brassicicola germinate over a wide range of temperatures, with the optimum at 28 to $31^{\circ} \mathrm{C}$. Infection is optimal at $25^{\circ} \mathrm{C}$, but infections can occur at temperatures as low as $10^{\circ} \mathrm{C}$. Moisture is required for germination, infection, and sporulation. A. brassicicola can overcome adverse conditions by infecting plants during several short wet periods instead of one continuous wet period. However, interrupted wet periods result in fewer infections than continuous wetness of the same duration (17). Sporulation can occur over a wide range of temperatures and is optimal at 20 to $30^{\circ} \mathrm{C}$. Spore dispersal occurs during the warmest and driest part of the day, and night dispersal is rare. In England, the highest spore catches of A. brassicicola occurred after a period of rain or prolonged leaf wetness (lasting more than $3 \mathrm{~h}$ ) with a mean temperature above $13^{\circ} \mathrm{C}(17)$.

Growers attempt to control Alternaria leaf spot with multiple fungicide applications $(1,9,16)$. In New York, the majority of storage cabbage producers apply two to three fungicide sprays, and a few growers make as many as five to seven fungicide applications. In recent years, Alternaria leaf spot incidence and severity have increased, particularly among fresh market and storage cabbage cultivars. Some growers have been unable to control Alternaria leaf spot with registered fungicides, and failure to control the disease appeared to be most common in cabbage fields with flea beetle (Phyllotreta cruciferae Goeze) infestations. The objective of this study was to determine whether there is an association between flea beetle infestations and incidence of Alternaria leaf spot, and whether flea beetles can transmit A. brassicicola to cabbage.

\section{MATERIALS AND METHODS}

Flea beetle isolations. Cabbage (cv. Brutus; Seedway, Hall, NY) was seeded in cell packs on 8 May 1995 and transplanted on 12 June into a field at the New York State Agricultural Experiment Station in Geneva. Alternaria leaf spot symptoms were first observed 50 days after transplanting. Natural infestations of flea beetles were observed feeding on infected plants (Fig. 1A and B) and were collected in glass vials from the plants on 7 and 18 August. The flea beetles were etherized for 3 min, placed on Difco Bacto potato dextrose agar (PDA) containing $0.01 \%$ streptomycin sulfate and $0.01 \%$ chlorampheni$\mathrm{col}$, and incubated 7 days at room temperature $\left(20\right.$ to $\left.26^{\circ} \mathrm{C}\right)$. The number of flea beetles yielding colonies of $A$. brassicicola was recorded.

The experiment was repeated in 1996. Cabbage (cv. Amtrak; Seedway) was seeded in cell packs on 16 May and transplanted on 18 June into the high-inoculum field used the previous year. In addition, cabbage was planted in a fallow field where tomatoes were grown the previous year. This location served as a low-inoculum (no previous history of $A$. brassicicola) field. Natural populations of flea beetles were present in both fields. Flea beetles were collected from both fields nine times during the growing season on 3 and 17 July; 6, 13, and 20 August; 2, 10, and 24 September; and 8 October. The flea beetles were captured in glass vials from cabbage plants and etherized, and 64 flea beetles were placed on agar media for isolation of A. brassicicola on each sampling date. After 7 days, the number of flea 
beetles yielding colonies of $A$. brassicicola was recorded.

Transmission to whole plants. Cabbage (cv. Lennox; Seedway) was seeded on 31 August 1995 in Cornell peat-vermiculite potting mix in $11-\mathrm{cm}$-diameter square plastic pots (three seeds per pot). When plants were 14 to 40 days old, 8 to 10 liv- ing flea beetles were collected in glass vials from infected cabbage (cv. Brutus) in a field located in Geneva. Pots containing healthy cabbage plants were placed in individual plastic bags, and one vial containing flea beetles was placed on the soil surface and opened. The bag immediately was sealed to prevent the flea beetles from escaping, and the pot was placed on a greenhouse bench shaded with wooden lathe. The greenhouse temperature ranged from 18 to $29^{\circ} \mathrm{C}$. The flea beetles fed on the healthy plants for 6 days. Four New York isolates $(703,707,759$, and 772) of A. brassicicola were grown on PDA for 4 to 14 days, and a mixture of the isolates
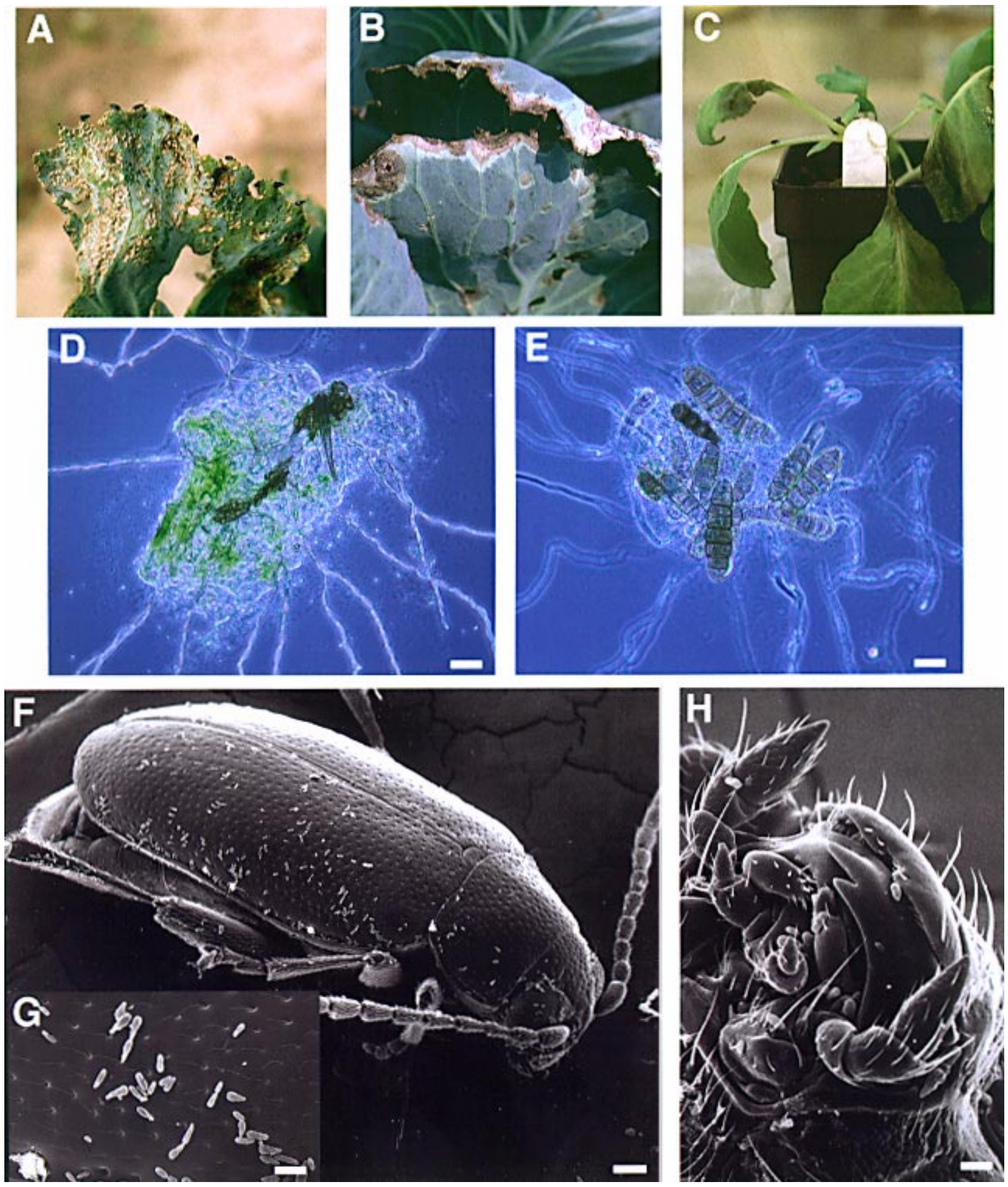

Fig. 1. The association between flea beetle (Phyllotreta cruciferae) feeding behavior and development of Alternaria leaf spot caused by Alternaria brassicicola. (A) Flea beetles feeding on cabbage leaves in the field. Note the extensive feeding along the leaf margin. (B) Development of Alternaria leaf spot on the leaf margin. (C) Alternaria leaf spot development on greenhouse plants infested with naturally contaminated flea beetles collected from infested fields. (D) Germinating conidia and undigested cabbage pieces in flea beetle feces. Bar $=40 \mu \mathrm{m}$. (E) Germinating conidia of A. brassicicola in flea beetle feces. Bar $=18 \mu \mathrm{m}$. (F) Flea beetle contaminated with conidia of A. brassicicola . Bar $=185 \mu \mathrm{m}$. (G) Conidia of A. brassicicola on flea beetle wing. Bar $=$ $70 \mu \mathrm{m}$. (H) Flea beetle mouthparts contaminated with conidia of A. brassicicola. Bar $=35 \mu \mathrm{m}$. 
containing $6.9 \times 10^{5}$ to $1.9 \times 10^{6}$ conidia per $\mathrm{ml}$ was used to inoculate one treatment to determine if environmental conditions were conducive for development of Alternaria leaf spot. Immediately after inoculation, the bags were sealed and placed on a shaded greenhouse bench. The three treatments (noninoculated control, inoculated control, noninoculated plants exposed to field-collected flea beetles) were arranged in a randomized design in the greenhouse, eight pots per treatment. Cabbage plants in all treatments were rated for disease incidence and severity after 9 to 13 days. Severity was determined on a scale of 0 to 9 , as follows: $0=$ healthy, no apparent disease; 1 $=<5$ pinpoint lesions (flecks); $2=6$ to 10 flecks; $3=11$ to 15 flecks; $4=>15$ flecks or a few large concentric-ring lesions; $5=$ moderate flecking or a few large lesions; $6=$ heavy flecking or moderate larger lesions; 7 $=$ heavy flecking or many large lesions with mild tissue collapse; $8=$ heavy flecking or many large lesions with moderate tissue collapse; and $9=$ heavy flecking or many large lesions with extensive tissue collapse. Isolations were made from symptomatic tissue on PDA containing streptomycin sulfate $(0.01 \%)$ and chloramphenicol $(0.01 \%)$. The experiment was repeated.

In 1996, cabbage (cv. Amtrak) was seeded on 5 July in Cornell peat-vermiculite potting mix in $11-\mathrm{cm}$-diameter square plastic pots (four seeds per pot). When the plants were 30 days old, eight living flea beetles per vial were collected from a field of infected cabbage (cv. Amtrak) in Geneva, bagged with healthy (greenhouse grown) cabbage plants on 5, 13, and 23 August and 2, 10, and 24 September, and placed on a shaded greenhouse bench. On the same dates, flea beetles were also collected from a low-inoculum field of cabbage, bagged with healthy cabbage plants, and placed on a shaded greenhouse bench. Additional treatments included a noninoculated control and an inoculated $(1.2 \times$ $10^{5}$ conidia per ml) control. After 10 days,

Table 1. Development of Alternaria leaf spot on noninoculated noninfested cabbage plants, on plants inoculated with Alternaria brassicicola, and on plants infested with contaminated flea beetles (Phyllotreta cruciferae) in 1995

\begin{tabular}{lccc}
\hline & \multicolumn{3}{c}{ Severity rating $^{\mathbf{a}}$} \\
\cline { 2 - 4 } Treatment & Experiment 1 & Experiment 2 & Experiment 3 $^{\text {Experime }}$ \\
\hline Noninoculated (no flea beetles) $_{\text {nnoculated }^{\mathrm{b}}}$ & 0.1 & 0.0 & 0.0 \\
Flea beetle transmitted $^{\mathrm{c}}$ & 7.1 & 8.5 & 8.8 \\
LSD $(P=0.05)$ & 5.2 & 5.6 & 6.5 \\
\hline
\end{tabular}

a Severity ratings were recorded 9 to 13 days after flea beetles were transferred to healthy greenhouse plants. Severity was determined on a scale of 0 to 9 , as follows: $0=$ healthy, no apparent disease; 1 $=<5$ pinpoint lesions (flecks); $2=6$ to 10 flecks; $3=11$ to 15 flecks; $4=>15$ flecks or a few large concentric-ring lesions; $5=$ moderate flecking or a few large lesions; $6=$ heavy flecking or moderate larger lesions; $7=$ heavy flecking or many large lesions with mild tissue collapse; $8=$ heavy flecking or many large lesions with moderate tissue collapse; and $9=$ heavy flecking or many large lesions with extensive tissue collapse.

${ }^{\mathrm{b}}$ Greenhouse cabbage plants were inoculated with A. brassicicola at $6.9 \times 10^{5}$ to $1.9 \times 10^{6}$ conidia per ml.

${ }^{\mathrm{c}}$ Flea beetles were captured from cabbage plants infected with A. brassicicola in the field and transferred to healthy greenhouse plants. two-sided transparent tape on stubs, then sputter-coated with platinum in an argon atmosphere with a Balzers SCD 040. The flea beetles and conidia were viewed with a Hitachi S-530 scanning electron microscope (Tokyo, Japan), and photographs were taken with a Polaroid 545 Land Camera and Polaroid 55 film.

\section{RESULTS}

Flea beetle isolations. $A$. brassicicola was isolated from flea beetles captured in fields with Alternaria leaf spot (Fig. 1A and B). In the first test conducted in 1995, A. brassicicola was isolated from 13 out of $69(18.8 \%)$ flea beetles, and in the second test, the fungus was isolated from 38 out of $132(28.8 \%)$ flea beetles. In 1996, flea beetles were collected nine times during the growing season, and isolations were made from etherized flea beetles. Isolation frequency from flea beetles increased as the crop approached maturity. A. brassicicola was recovered from $0,1,2,6,3,16$, 31,44 , and 49 out of 64 flea beetles on 3 and 17 July; 6, 13, and 20 August; 2, 10, and 24 September; and 8 October, respectively. In the cabbage field with no previous history of Alternaria leaf spot, the isolation frequency increased as the season progressed, but at a much slower rate. $A$. brassicicola was recovered from $0,0,0,1$, $0,1,0,0$, and 14 out of 64 flea beetles captured on 3 and 17 July; 6, 13, and 20 August; 2, 10, and 24 September; and 8 October, respectively.

Transmission to whole plants. The flea beetles preferred to feed on the leaf margins but also fed on the leaf surface (Fig. 1C). Feeding injury varied markedly among plants. In 1995, Alternaria leaf spot severity was high on plants inoculated with A. brassicicola and on noninoculated plants infested with flea beetles captured from cabbage with Alternaria leaf spot (Table 1). Alternaria leaf spot was observed and verified by isolation from one of the noninoculated, noninfested (no flea beetles) control plants in the first experiment conducted in 1995.

In 1996, Alternaria leaf spot developed on greenhouse plants that were infested with flea beetles obtained from low- and high-inoculum cabbage fields (Fig. 2). Alternaria leaf spot severity on the greenhouse plants increased as the crops approached maturity and as disease incidence and severity on plants in both fields increased. The rate of increase in disease severity and the final disease severity rating were highest on greenhouse plants infested with flea beetles from the highinoculum field. Alternaria leaf spot developed on greenhouse plants infested with flea beetles obtained from the low-inoculum field, but disease severity was less. Mild symptoms of Alternaria leaf spot developed on noninoculated, noninfested control greenhouse plants on three dates, and the disease was verified by isolation of 
A. brassicicola (data not shown). Alternaria leaf spot was severe on plants inoculated with conidia of $A$. brassicicola (data not shown).

$A$. brassicicola in feces and in the digestive tract of flea beetles. Conidia of $A$. brassicicola and undigested pieces of cabbage leaf were observed in flea beetle feces obtained from flea beetles that previously had fed on infected plants in the field (Fig. $1 \mathrm{D}$ and E). Most conidia were intact, although a few were observed that were broken. Some conidia germinated on the glass slides that were used to collect the feces in the moist plastic boxes. Isolations from the digestive tract of flea beetles resulted in cultures of $A$. brassicicola from 2 of 19 flea beetles tested.

External $A$. brassicicola on flea beetles. Conidia of A. brassicicola were observed and photographed on all parts of the flea beetle bodies (Fig. 1F), including wings (Fig. 1G), mouthparts (Fig. 1H), antennae, and legs. A. brassicicola conidia accumulated in cavities of the flea beetle exoskeleton and in general were distributed on all parts of the flea beetles.

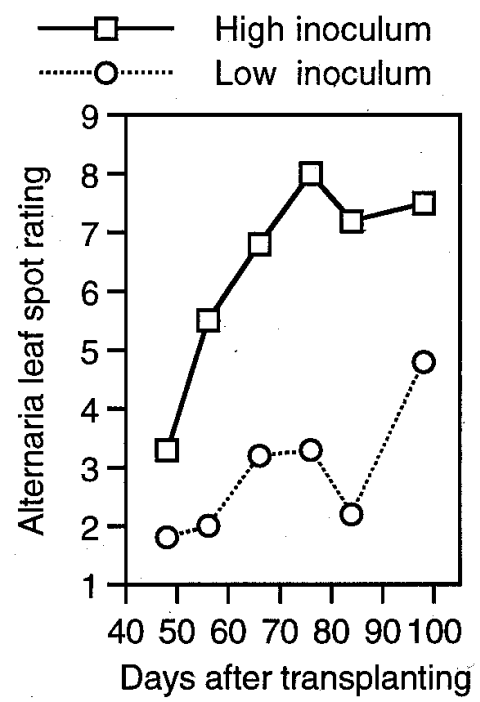

Fig. 2. Transmission of Alternaria brassicicola to healthy cabbage plants in the greenhouse by flea beetles (Phyllotreta cruciferae) captured in high-inoculum fields and low-inoculum fields of cabbage in 1996. Field with infected cabbage resulting from overwintered inoculum is referred to as a high-inoculum field, and field with no known history of Alternaria leaf spot is referred to as a low-inoculum field. Severity ratings were recorded 14 to 21 days after transferring flea beetles to healthy greenhouse plants. Severity was determined on a scale of 0 to 9 , as follows: $0=$ healthy, no apparent disease; $1=<5$ pinpoint lesions (flecks); $2=6$ to 10 flecks; $3=11$ to 15 flecks; $4=>15$ flecks or a few large concentric-ring lesions; $5=$ moderate flecking or a few large lesions; $6=$ heavy flecking or moderate larger lesions; $7=$ heavy flecking or many large lesions with mild tissue collapse; $8=$ heavy flecking or many large lesions with moderate tissue collapse; and $9=$ heavy flecking or many large lesions with extensive tissue collapse.

\section{DISCUSSION}

Results from this study clearly demonstrate that flea beetles can transmit A. brassicicola to cabbage. The most compelling data in support of this association is that flea beetles captured in cabbage fields with Alternaria leaf spot transmitted A. brassicicola to healthy cabbage plants in controlled experiments. In addition, conidia of A. brassicicola were observed on the surface of flea beetle bodies and within flea beetle feces, and feeding injuries along leaf margins were frequently the site of ingress for the fungus and subsequent development of Alternaria leaf spot. The salivary and complex digestive fluid in which the conidia were deposited and the fluid exuded from wounded areas on the leaves were likely sources of moisture and nutrients for the germinating conidia.

We propose that flea beetle transmission of $A$. brassicicola to cabbage may occur in four ways. First, conidia of A. brassicicola were observed on all parts of the flea beetle bodies, and passive deposition of inoculum to the leaf and stem surfaces of healthy plants was probable. Second, flea beetle feeding sites provided sites of ingress for conidia that passively detach from the flea beetle. Third, intact and broken conidia of $A$. brassicicola were observed in flea beetle feces that obviously were viable after passing through the flea beetles, as evidenced by their germination on the glass slides used for collecting the feces. Finally, mouthparts of flea beetles were contaminated with spores of $A$. brassicicola. With a dissecting scope, we observed flea beetles removing conidia from their antennae by passing them through the mouthparts. This behavior would increase the inoculum level in and around the mouthparts that were used to feed on cabbage plants.

Both $A$. brassicicola and $P$. cruciferae have been previously implicated in vectorpathogen relationships. Transmission of $A$. brassicicola to cabbage by an invertebrate was previously reported when viable conidia were recovered from the digestive tract and excrement of slugs (7). The flea beetle ( $P$. cruciferae) was previously reported to transmit Xanthomonas campestris pv. campestris, the causal agent of black rot on crucifers (18). In contrast to our studies, black rot did not develop when flea beetles collected in fields with black rot were transferred to healthy plants in the greenhouse. Transmission only occurred when the flea beetles were sprayed with a bacterial suspension before transfer to healthy plants.

There are many examples of insect-assisted dispersal and deposition of fungal inoculum. Puncture wounds on muskmelon leaves caused by adult female leaf miners (Liriomyza trifolii) provided sites for ingress by $A$. cucumerina and significantly increased the incidence of Alternaria leaf blight lesions (3). Feeding injury by adult bean leaf beetles on pods resulted in an increased recovery of fungi from soybean seeds (19). Nine species of fungi, including A. tenuissima, were isolated from the head and abdomen of surface-sterilized bean leaf beetles. Flea beetle (Epitrix cucumeris) feeding injury on tomato plants resulted in wounds that were colonized by A. solani (8). Disease control was significantly improved by adding an insecticide to the scheduled copper sprays to control the flea beetles. Insect feeding injury on cabbage caused by larvae of imported cabbageworm (Pieris rapae), the diamondback moth (Plutella xylostella), and the cabbage looper (Trichoplusia ni) provided sites for ingress by Sclerotinia sclerotiorum and increased incidence of Sclerotinia rot on cabbage (5). Several species of fungi were isolated from discolored rice kernels and from stylets and saliva of the rice stink bug (Oebalus pugnax) (13). The density of rice stink bug infestations was correlated with incidence of discolored rice kernels.

Inoculum of fungal pathogens carried internally by insects has also been reported. In a recent study, Fusarium glume spot of wheat caused by Fusarium poae was associated with the mycophageous mite Siteroptes avenae (10). The mite stored microconidia of the fungus internally in two elongated sporothecae. Conidia of Botrytis cinerea (causal agent of bunch rot of grapes) were carried externally on the cuticle of the fruit fly (Drosophila melanogaster) and internally through the digestive tract (14). Similarly, external and internal inoculum were documented for Alternaria species associated with the cotton boll weevil (Anthonomus grandis) (17) and in our study with $A$. brassicicola and $P$. cruciferae.

Sources of $A$. brassicicola inoculum include infested debris in soil, infected weeds and nearby crucifer crops, and contaminated seed $(11,12,15,17,20)$. Weeds have been identified as a source of inoculum for $S$. sclerotiorum (6) but have not been documented as sources of A. brassicicola in New York to date. In our study, infection in the noninoculated, noninfested control plants presumably resulted from contaminated seed. A. brassicicola was isolated on amended PDA from 3\% $(16 / 530$ and $11 / 350)$ of the seeds in 1995 and 0.5 to $1.5 \%(1 / 200$ and $3 / 200)$ of the seeds in 1996.

Control of $A$. brassicicola on cabbage is difficult because the environmental conditions favorable for growth of cabbage (cool and moist) are favorable for growth of the fungus $(2,9,11)$, there are multiple sources of the pathogen $(1,2,12,15,20)$, and the conidia can travel distances of $1,800 \mathrm{~m}$ (17). Multiple applications of protectant fungicides are required to achieve economic yield and acceptable quality in infected crops $(1,9,16)$. The most economical 
method for controlling A. brassicicola is to plant resistant cultivars $(4,11,17)$. A recent study identified 15 accessions of $B$. oleracea and one accession of $B$. napus that exhibited partial resistance to $A$. brassicicola (11). No Brassica accessions were found to possess immunity to A. brassicicola, but the resistance exhibited by most accessions was found to be stable and heritable. In another study, imported cabbageworm larvae ( $P$. rapae) and cabbage aphids (Brevicoryne brassicae) were reduced by 80 and $95 \%$ in natural infestations on glossy lines of Brassica oleracea (21). However, the glossy and trichomebearing lines studied to date were highly susceptible to flea beetles ( $P$. cruciferae and $P$. striolata) and to Alternaria leaf spot caused by A. brassicicola and A. brassicae $(11,21)$

This is the second report demonstrating transmission of $A$. brassicicola by an invertebrate (7). Results from our field and greenhouse studies indicate there is significant potential for flea beetle transmission of A. brassicicola. We believe this association may explain in part the inability of some growers to control Alternaria leaf spot on cabbage.

\section{ACKNOWLEDGMENTS}

The authors gratefully acknowledge M. Miller and $\mathrm{H}$. Hoch for microscopy assistance, A. Shelton, W. Wilsey, J. Tang, and T. Mosher for advice on flea beetle behavior, and the summer assistance of D. Cobb, P. Cobb, D. Hoffman, K. McCormick, and J. Seem. This research was supported in part by the New York State Cabbage Research Association and Cornell Cooperative Extension.

\section{LITERATURE CITED}

1. Babadoost, M., Gabrielson, R. L., Olson, S. A., and Mulanax, M. W. 1993. Control of Alternaria diseases of brassica seed crops caused by Alternaria brassicae and Alternaria brassicicola with ground and aerial fungicide applications. Seed Sci. Technol. 21:1-7.

2. Bassey, E. O., and Gabrielson, R. L. 1983. The effects of humidity, seed infection level, temperature and nutrient stress on cabbage seedling disease caused by Alternaria brassicicola. Seed Sci. Technol. 11:403-410.

3. Chandler, L. D., and Thomas, C. E. 1991. Effect of leaf miner feeding activity on the incidence of Alternaria leaf blight lesions on muskmelon leaves. Plant Dis. 75:938-940.

4. Dillard, H., Cobb, A., McCormick, K., Hoffman, D., Seem, J., and Ntahimpera, N. 1996. Reaction of cabbage cultivars to Alternaria leaf spot, 1995. Biol. Cult. Tests 11:99.

5. Dillard, H. R., and Cobb, A. C. 1995. Relationship between leaf injury and colonization of cabbage by Sclerotinia sclerotiorum. Crop Prot. 14(8):677-682.

6. Dillard, H. R., and Hunter, J. E. 1986. Association of common ragweed with Sclerotinia rot of cabbage in New York State. Plant Dis. 70:26-28.

7. Hasan, S., and Vago, C. 1966. Transmission of Alternaria brassicicola by slugs. Plant Dis. Rep. 50:764-767.

8. Heuberger, J. W., and Dimond, A. E. 1941. Relation of flea beetle control to control of Alternaria solani on tomatoes. Plant Dis. Rep. 25:415-418.

9. Humpherson-Jones, F. M. 1991. The development of weather-related disease forecasts for vegetable crops in the UK: Problems and prospects. Bull. OEPP/EPPO Bull. 21:425-429.

10. Kemp, G. H. J., Pretorius, Z. A., and Wingfield, M. J. 1996. Fusarium glume spot of wheat: A newly recorded mite-associated disease in South Africa. Plant Dis. 80:48-51.

11. King, S. R. 1994. Screening, selection, and genetics of resistance to Alternaria diseases in Brassica oleracea. Ph.D. thesis. Cornell Uni- versity, Ithaca, NY.

12. Knox-Davies, P. S. 1979. Relationships between Alternaria brassicicola and Brassica seeds. Trans. Br. Mycol. Soc. 73:235-248.

13. Lee, F. N., Tugwell, N. P., Fannah, S. J., and Weidemann, G. J. 1993. Role of fungi vectored by rice stink bug (Heteroptera: Pentatomidae) in discoloration of rice kernels. J. Econ. Entomol. 86(2):549-556.

14. Louis, C., Girard, M., Kuhl, G., and LopezFerber, M. 1996. Persistence of Botrytis cinerea in its vector Drosophila melanogaster. Phytopathology 86:934-939.

15. Maude, R. B., and Humpherson-Jones, F. M 1980. Studies on the seedborne phases of dark leaf spot (Alternaria brassicicola) and gray leaf spot (Alternaria brassicae) of brassicas. Ann. Appl. Biol. 95:311-319.

16. Miller, M. E. 1994. Evaluation of fungicides for Alternaria leaf spot control in cabbage, 1993. Fungic. Nematicide Tests 9:100.

17. Rotem, J. 1994. The genus Alternaria: Biology, epidemiology, and pathogenicity. American Phytopathological Society, St. Paul, MN.

18. Shelton, A. M., and Hunter, J. E. 1985 Evaluation of the potential of the flea beetle Phyllotreta cruciferae, to transmit Xanthomonas campestris pv. campestris, causal agent of black rot of crucifers. Can. J. Plant Pathol. 7:308-310.

19. Shortt, B. J., Sinclair, J. B., Helm, C. G Jeffords, M. R., and Kogan, M. 1982. Soybean seed quality losses associated with bean leaf beetles and Alternaria tenuissima. Phytopathology 72:615-618.

20. Sivapalan, A. 1993. Fungi associated with broccoli seed and evaluation of fungal antagonists and fungicides for the control of seed-borne Alternaria brassicicola. Seed Sci. Technol. 21:237-245.

21. Stoner, K. A. 1992. Density of imported cabbageworms (Lepidoptera: Pieridae), cabbage aphids (Homoptera: Aphididae), and flea beetles (Coleoptera: Chrysomelidae) on glossy and trichome-bearing lines of Brassica oleracea. J. Econ. Entomol. 85(3):1023-1030. 